Emanuel V. Towfigh

\title{
Das Parteien-Paradox
}

Ein Beitrag zur Bestimmung des Verhältnisses von Demokratie und Parteien

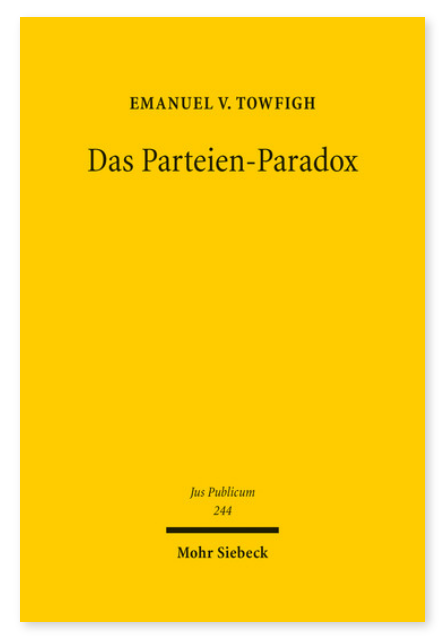

2015. XV, 286 Seiten. JusPubl 244

ISBN 978-3-16-153698-4

DOI 10.1628/978-3-16-153698-4

eBook PDF

ISBN 978-3-16-153697-7

Leinen $104,00 €$
Demokratien weisen überall in der Welt Krisensymptome auf: Wahlbeteiligung, Akzeptanz politischer Entscheidungen und Vertrauen in die politischen Institutionen sinken stetig. Doch der Verdruss gilt nicht Demokratie und Politik, sondern Parteien und Politikern. Hier setzt Emanuel V. Towfigh an und geht der Frage nach, in welchem Verhältnis die grundgesetzliche Konzeption von Demokratie zu ihrer institutionellen Umsetzung steht. Zunächst rekonstruiert er das vorherrschende Leitbild der demokratischen Ordnung, demzufolge der politische Wettbewerb widerstreitende Interessen zu gemeinwohldienlichen Entscheidungen aggregiert. Aber auch negative Wirkungen der politischen Parteien lassen sich, gleichsam spiegelbildlich, auf das überkommene Leitbild zurückführen. Politische Parteien haben also eine paradoxe Wirkung: Demokratische Entscheidungen lassen sich heute nicht ohne sie legitimieren, aber sie bescheren gleichzeitig dramatische Legitimationsprobleme. Will man die negativen Wirkungen der Parteien reduzieren, bedarf es einer Neuausrichtung des Leitbildes von Demokratie, für die die Arbeit erste Fluchtpunkte formuliert.

Emanuel V. Towfigh Geboren 1978; Studium der Rechtswissenschaften in Münster und Nanjing; 2005 Promotion zum Dr. iur.; nach dem Referendardienst Post-Doc am Max-Planck-Institut zur Erforschung von Gemeinschaftsgütern in Bonn, an der New York University und an der University of Virginia; 2014 Habilitation; seit 2016 Inhaber des Lehrstuhls für Öffentliches Recht, Empirische Rechtsforschung und Rechtsökonomik an der Law School und Professor für Rechtsökonomik an der Business School, EBS Universität Wiesbaden.

Jetzt bestellen:

https://mohrsiebeck.com/buch/das-parteien-paradox-9783161536984?no_cache=1

order@mohrsiebeck.com

Telefon: $+49(0) 7071-923-17$

Telefax: $+49(0) 7071-51104$ 